altered by some morbid affections. In consequence of the action of such hardening agents as alcohol, chromic acid, bichromate of potash and ammonia, osmic acid and others, we have to deal with so many changes of the normal structure, that the true anatomical conditions are demonstrated, sometimes only with great difficulty. The examination of the fresh tissues, however, in indifferent liquids, as water, albumen, gelatine, blood-serum, \&c., should never be neglected, as it is by the em. ployment of as many different methods of examination as possible, and by the application of theories carefully deduced therefrom, that we will be able to throw further light on regions so attractive to the student of histology.

[To be continued in the April number.]

\title{
TWO CASES OF PARALYSIS.
}

BY DANIEL H. KITCHEN, M. D., Assistant Physician of the New York State Lunatic Asylum.

Case I. Lead Paralysis. Woman, age twenty, sin. gle, housework. Patient usually enjoyed good health up to the fall of $18 \tau 1$, when she was attacked with brachial neuralgia and suffered almost constant pain. From this time, she began to run down in her general health, lost appetite, and began to sleep irregularly. She took large doses of opium and morphine to allay the pain. Her complexion became so sallow that she began the use of powdered white lead, by rubbing a few grains over her face daily ; says a number of ounces were absorbed in this way. Early in the spring of 1872 , stopped the local application of lead, and for a month following took a few grains by the mouth each day. In June following, she had paralysis of both 
hands, with slight attacks of colic. The paralysis of the extensors of the hands and fingers was complete, so that the hands hung down helplessly. No special treatment was pursued till August, 1873. During this interval she suffered a great deal of pain and colic, and required all the care of a child. When we first saw her, her condition was as follows: she was pale, anæmic and emaciated, conjunctivæ pearly, blue line on gums, the paralysis of both hands complete so that they were a dead weight, with marked loss of sensation, from the elbows to the ends of the fingers. She had to be dressed, undressed, and fed, and her weight which in health was 130 pounds, was at this time 96 pounds.

We began at once the application of the Faradic current, about ten minutes each day, the current directed from the elbow to the ends of the fingers. It was fully three weeks before any perceptible benefit was observed; then she began to flex the fingers slightly and had slight motion of the wrist. Not receiving as much benefit as we had anticipated from the Faradic current, we substituted the Galvanic and it has been continued regularly, every second day. At first we used sixteen cells of the Stöhrer battery, and gradually increased the number to thirty-two. From the time of the change of the current, her appetite increased, her general health steadily improved and sensation began to return. November the 1st, her weight was 110 pounds. About the middle of November, she could raise the hands to a level of the arms, hut had not sufficient strength to retain them in that position for any length of time. At the time of writing, the sensation is perfectly normal, the muscles of the arms and hands are full and firm, and she has full use of the hands; can dress herself, goes to the table and uses her knife and fork as well as ever. Her weight is now 122 pounds, color 
healthy, and she is apparently in her usual health. We propose, however, to continue the use of the current for a time, making an application once a week.

In most instances of lead poisoning, the metal enters the system by inhalation. In this case sufficient was absorbed by rubbing and internal use to produce paralysis. It will be observed that the paralysis affected only the muscles of the forearm and hand, leaving all the other muscles intact.

Neuralgia which almost invariably follows the poisoning by lead, in this instance preceded the paralysis, which was undoubtedly due to the gradual poisoning.

Case II. Paralysis of Left Leg with Progressive Muscular Atrophy. This is the case of a young woman, in apparent good health. While walking up stairs about eight years ago, was suddenly seized with paralysis of the left limb. From that time up to August last, the limb was simply a dead weight, and her case was considered one of hip.joint disease. During all this time there was complete loss of sensation and power, the limb was atrophied and surface cold. With the assistance of a cane she walked with great difficulty, by throwing the foot and leg forward by the muscles of the hip. Her physical health ran down, and she became pale and anæmic.

In August, 1873, the healthy limb measured as follows:

At ankle joint, seven and one half inches.

At calf, twelve and a half inches.

Just above the knee, fourteen and a half inches.

Middle of thigh, nineteen inches.

Measurements of the paralyzed limb at the same time:

At ankle joint, seven inches.

At calf, ten and a half inches.

Just above the knee, twelve and a half inches.

Middle of thigh, fifteen and a half inches. 
Her weight was 105 pounds. She was pale, emaciated and very anæmic, appetite variable. The left limb was completely paralyzed, the knee, ankle and joints of the toes could not be moved by the will. The surface was cold and the muscles atrophied, as the above measurements plainly show.

On the 15th of August, we began with the constant current, using sixteen cells of the Stöhrer battery. The application was made for fifteen minutes every day, the current being passed from the hip to the toes, and particularly through the knee and ankle joints.

September 15th, the measurements of the paralyzed limb were as follows:

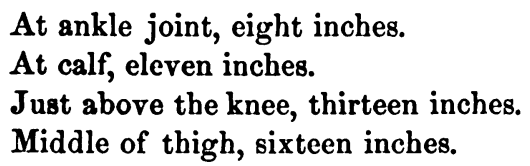

The circulation was gradually being restored, the limb was covered with a moist warm perspiration and the muscular contractions quite perceptible. She had partial use of the ankle joint and could move the toes readily, but there was no sensation.

October 15th, measurements as follows:

At ankle joint, eight inches.

At calf, eleven inches.

Just above the knec, thirteen and three-quarters inches.

Middle of thigh, sixteen inches.

Her weight at this time was 118 pounds; appetite increased, gait improved, could walk a distance of two miles with ease. At this time we began the use of the metallic plate, placing the paralyzed foot on the plate, and passing the electrode over the muscles of the limb. The number of cells was now increased to thirty-two, and twice a week, instead of using the sponge, we substituted the metallic brush. 
November 15th, measurements as follows:
At ankle joint, eight inches.
At calf, eleven inches.
Just above the knee, fourteen and one-eighth inches.
Middle of thigh, eighteen inches.

Weight 119 pounds. Her physical health good, all the functions normal, sensation fully restored and the temperature the same as that of the healthy limb. The current still used every day.

December 15th, measurements as follows:

At ankle joint, eight and a half inches.

At calf, eleven and three-quarters inches.

Just above the knee, thirteen and three-quarters inches.

Middle of thigh, eighteen an: a half inches.

Weight, 119 pounds; appetite good, and improvement continues. At the time of writing, 120 applications of electricity have been made. The rapid development of the muscles is shown by a glance at the measurements. The patient has full control over the various joints, and can now move the limb about freely, though some lameness continues.

In this case there have been no neuralgic pains, but anæesthesia was profound. The galvanism has served a double purpose in restoring the general health, by improving digestion, \&c., as well as serving the direct purpose of a nerve tonic, and restoring the atrophied muscles to their normal size.

This case was one of spontaneous paralysis. The reflex excitability was not impaired. When the electric current was passed through the paralyzed muscles, she felt them move, and it was risible to the naked eye, and with either the rapid intermissions of the Faradic, or with the constant current, not the least pain was felt, while the same current applied to the healthy limb pro. duced not only unpleasant sensations, but even pain. 